\title{
Violence Victimization of Young Men in Heterosexual Relationships: Does Alcohol Outlet Density Influence Outcomes?
}

\author{
Martha W. Waller, PhD, \\ Pacific Institute for Research and Evaluation, Chapel Hill, North Carolina \\ Bonita J. Iritani, MA, \\ Pacific Institute for Research and Evaluation, Chapel Hill, North Carolina \\ Robert L. Flewelling, PhD, \\ Pacific Institute for Research and Evaluation, Chapel Hill, North Carolina \\ Sharon L. Christ, PhD, \\ Purdue University, West Lafayette, Indiana
}

Carolyn Tucker Halpern, PhD, and

University of North Carolina at Chapel Hill

Kathryn E. Moracco, PhD

University of North Carolina at Chapel Hill

\begin{abstract}
This study examined whether alcohol outlet density is associated with male physical and sexual victimization by a female partner. Data were from the National Longitudinal Study of Adolescent Health (Add Health). A total of 3,179 young adult men identified a current heterosexual relationship and had complete intimate partner violence (IPV) victimization data. Almost $16 \%$ of this sample reported being the victim of physical only IPV in their relationship over the previous 12 months; an additional $6.4 \%$ were victims of sexual only or sexual and physical IPV.

Multivariate analyses indicated high alcohol outlet density was associated with greater odds of experiencing physical IPV only (odds ratio $[O R]=2.07$ ). Heavy drinkers experienced increased odds of physical and sexual IPV victimization. Alcohol outlet density should be addressed in prevention efforts.
\end{abstract}

\section{Keywords}

intimate partner violence; neighborhoods; young adulthood; drinking; alcohol use; male victimization

The association of alcohol use with intimate partner violence (IPV) is well documented in the research literature (Caetano, Vaeth, \& Ramisetty-Mikler, 2008; Cunradi, Caetano, \& Schafer, 2002a; Lipsky, Caetano, Field, \& Bazargan, 2005; Lipsky, Caetano, Field, \& Larkin, 2005). In addition, there is a strong evidence linking alcohol outlet density with increased alcohol consumption as well as criminal violence, but there are far fewer studies 
linking outlet density to IPV (Chen, Grube, \& Gruenewald, 2010; Cunradi, Mair, Ponicki, \& Remer, 2011; Gorman, Labouvie, Speer, \& Subaiya, 1998; Livingston, 2010; McKinney, Caetano, Harris, \& Ebama, 2009; Treno, Ponicki, Remer, \& Gruenewald, 2008). Based on the important association between alcohol consumption and IPV, along with the association between alcohol outlet density and increased drinking and criminal behavior, it stands to reason that alcohol outlet density influences IPV as well, although the path through which density influences IPV is not entirely clear. There is also little research examining correlates of IPV victimization among males despite research suggesting that male victims may well experience psychological consequences resulting from IPV similar to females (Chan, Straus, Brownridge, Tiwari, \& Leung, 2008; Coker et al., 2002; Coker, Weston, Creson, Justice, \& Blakeney, 2005; Fletcher, 2010; Hines, Brown, \& Dunning, 2007; Hines \& MalleyMorrison, 2001; Randle \& Graham, 2011).

Cunradi (2010) recommended in her recent article exploring the research gaps that IPV research should attempt to understand the mechanisms through which outlet density and IPV are associated. Therefore, given a dearth of studies examining the link between alcohol outlet density and IPV and a lack of studies examining factors associated with male victimization, this study examines the associations between alcohol outlet density, drinking patterns, and male IPV victimization by a female partner.

\section{ALCOHOL USE AND INTIMATE PARTNER VIOLENCE VICTIMIZATION AMONG MALES}

The association between alcohol use and male perpetration of IPV has been well documented, and to a lesser extent, it has also been documented among female perpetrators and couples experiencing bidirectional or mutual IPV (Caetano, Ramisetty-Mikler, \& Field, 2005; Caetano, Ramisetty-Mikler, \& Harris, 2008; Cunradi, Caetano, Clark, \& Schafer, 1999; Foran \& O'Leary, 2008; McKinney, Caetano, Rodriguez, \& Okoro, 2010; Melander, Noel, \& Tyler, 2010; Peek-Asa et al., 2005; Thompson \& Kingree, 2006). Given the welldocumented association between alcohol use by females and their risk for IPV victimization, several recent studies have also examined the extent to which male drinking is associated with victimization of males by their female partners (Caetano, Field, Ramisetty-Mikler, \& McGrath, 2005; Cunradi, 2007, 2009; Fisher, Cullen, \& Turner, 2000; Foran \& O'Leary, 2008; Graham, Bernards, Wilsnack, \& Gmel, 2011; Leonard, 2005; Parkhill \& Abbey, 2008). However, findings in this latter literature are mixed.

Cunradi (2007) examined mutual IPV among a sample of Black, Hispanic, and White married or cohabiting adults in the 2000 National Household Survey on Drug Abuse (NHSDA). Cunradi (2007) examined the association between alcohol consumption and IPV after controlling for measures of social disorganization. The results showed that men's past 30-day drinking, heavy drinking, and binge drinking as well as past 12-month alcohol use were all significantly associated with greater odds of their experiencing bidirectional IPV when compared to abstainers and those who had not used alcohol in the past 12 months. Alcohol consumption and neighborhood disorder were independently associated with bidirectional IPV. Alternatively, only females in the most hazardous drinking category experienced greater risk for mutual IPV. Neighborhood disorder moderated the association between most female alcohol consumption and IPV such that risk for mutual IPV increased significantly as neighborhood disorder increased (Cunradi, 2007). The measures of IPV in the Cunradi (2007) study are limited to two questions: (a) How many times during the past 12 months did your spouse or partner hit or threaten to hit you? and (b) How many times during the past 12 months did you hit or threaten to hit your spouse or partner? By combining threatening IPV and physical IPV, we are unable to distinguish if alcohol use among men would be differentially associated with verbal versus physical IPV and, at least 
in this study, there is no distinction between perpetrators and victims of IPV because males and females are both within this context. Therefore, although this study does provide evidence that alcohol use by males is associated with mutual IPV, we are unable to assume and say with assurance that alcohol use by males increases the likelihood of experiencing male IPV victimization by a female partner.

Reed, Amaro, Matsumoto, and Kaysen (2009) also found significant positive associations for males between three measures of recent alcohol use and physical victimization, although their study did not explicitly examine victimization by a female partner. A study by McKinney and colleagues (2010) examined alcohol use among couples reporting bidirectional or unidirectional IPV using the revised Conflict Tactics Scale Form R. The authors found that $30 \%$ of couples reported alcohol use among either or both partners prior to the IPV incident and that alcohol use was associated with more severe IPV perpetration on the part of both males and females (McKinney et al., 2010). Interestingly, however, male alcohol use was not associated with experiencing IPV victimization by their female partner in models adjusted for demographic factors; yet, female alcohol use was associated with increased odds of perpetrating female-to-male partner violence (FMPV; McKinney et al., 2010). In fact, couples reporting severe as opposed to mild male-to-female partner violence (MFPV) or FMPV were more likely to report female alcohol involvement but not male (McKinney et al., 2010). Similarly, Cunradi (2009) examining Hispanic married or cohabiting adults from the 2000 NHSDA found that among males, drinking patterns did not increase their odds of IPV victimization.

Given these inconsistent findings in the literature, additional research on the influence of alcohol use among male victims of IPV by a female partner, separate from female perpetration of IPV, is warranted to simplify and shed light on the complexity of the relationship.

\section{ALCOHOL OUTLET DENSITY AND INTIMATE PARTNER VIOLENCE VICTIMIZATION}

The influence of alcohol outlet density in a neighborhood on risk behavior has been given considerable attention in the past decade. In the United States, these retail sources include on-premise alcohol outlets in which alcoholic beverages are consumed at the facility (e.g., restaurants and bars) and off-premise outlets in which the alcohol is bought for drinking at a different location (e.g., liquor stores and grocery stores). There is a growing body of research indicating that greater alcohol outlet density is associated with increases in problem drinking; more drinking and driving; and more violence, injury, and child neglect and maltreatment (Freisthler, Midanik, \& Gruenewald, 2004; Gruenewald, Freisthler, Remer, LaScala, \& Treno, 2006; Gruenewald \& Remer, 2006; Gruenewald, Remer, \& Lipton, 2002; Livingston, 2008a, 2008b; McKinney, Caetano, Harris, et al., 2009; Scribner et al., 2010; Scribner et al., 2008; Treno, Gruenewald, Remer, Johnson, \& LaScala, 2008).

The association between outlet density and IPV perpetration has also been examined, although to a far lesser extent. McKinney, Caetano, Harris, et al. (2009) examined data from a U.S. population-based sample of couples that were linked to alcohol outlet data and 1990 U.S. Census data. Items from the Conflict Tactics Scale Form $\mathrm{N}$ were used to measure both male and female perpetration and victimization over the past 12 months. They found in their adjusted models that for every increase of 10 alcohol outlets per 10,000 persons, there was a statistically significant 34\% increase in MFPV. In addition, an increase of 10 outlets per 10,000 people was associated with a $12 \%$ increase in FMPV, although this latter association was not statistically significant (McKinney, Caetano, Harris, et al., 2009). However, the association was moderated by drinking behavior such that the strongest association was 
found among couples reporting high-risk drinking behaviors. Although McKinney, Caetano, Harris, et al. (2009) examines FMPV as distinct from MFPV, they do not directly examine male victimization by their female partner. Yet, as was seen in the later McKinney and colleagues' (2010) study, the association with alcohol use differs on whether one is interested in victim or perpetrator. We cannot assume that alcohol use operates the same way among female perpetrators of FMPV as with male victims of FMPV.

Livingston (2010) also examined the link between alcohol outlet density and IPV reported to police in Melbourne, Australia controlling for other neighborhood risk factors including socioeconomic disadvantage, population turnover or instability, population density, and the proportion speaking a language other than English. In this cross-sectional study, he found that types of alcohol outlets were differentially associated with IPV. In this case, the density of general license outlets (i.e., pubs and taverns) was significantly associated with higher reports of IPV, and density of on-premise outlets (i.e., restaurants) was negatively associated with IPV reports after adjusting for the influences of other neighborhood level variables (Livingston, 2010). Livingston (2010) suggests a posteriori that general licensed outlets, which would represent outlets where the primary activity is drinking such as pubs, bars, and taverns, are associated with increased IPV because of the influence on one's routine drinking behavior. Alternatively, on-premise outlets, such as restaurants, are associated with lower IPV perhaps because the main focus is on something other than drinking alcohol and less alcohol is consumed. In other words, the density and type of alcohol outlet is associated with different drinking patterns leading to IPV.

Livingston (2011) also conducted a longitudinal analysis of alcohol outlet density and police reported domestic violence. Three types of outlets were examined: general licenses, on premise, and off premise. Combined, there was a significant relationship between alcohol outlet density and IPV over time after controlling for sociodemographics. However, the associations differed by type of outlet in the effect on police reported IPV. Similar to Livingston's (2010) cross-sectional study findings, general licenses were positively associated with IPV rates, whereas on-premise licenses were negatively associated. However, the density of packaged liquor outlets was not associated with IPV reports (Livingston, 2011).

In contrast, Cunradi and colleagues (2011) examined alcohol outlet density along with other neighborhood characteristics and the association with IPV measured by IPV-related calls to police. Using Bayesian space-time modeling, the researchers found that for each additional off-premise alcohol outlet, there was an associated 4\% increase in IPV-related calls. On the other hand, on-premise alcohol outlet had no significant association.

The influence of alcohol outlets density on IPV victimization among males remains uncertain. Furthermore, the influences by type of outlet vary across studies. Therefore, further research is needed to provide additional insight into the question of how alcohol outlet density is associated with male victims of IPV by a female partner.

\section{SOCIAL DISORGANIZATION AND INTIMATE PARTNER VIOLENCE VICTIMIZATION}

As previously alluded to, most studies that have examined influence of alcohol outlet density on various outcomes have treated other neighborhood characteristics as potential confounds. These have included neighborhood level measures of social disorganization such as perception of crime and drug selling in the neighborhood, vacant housing, graffiti, poverty, social cohesion, race/ethnicity distributions, single parent households, foreign born, and employment (Caetano, Ramisetty-Mikler, \& Harris, 2010; Cunradi, 2007, 2009, 2010; 
Cunradi, Caetano, Clark, \& Schafer, 2000; Cunradi et al., 2011; Livingston, 2010, 2011;

McKinney, Caetano, Harris, et al., 2009). Measures of neighborhood social disorganization have, on the whole, been associated with increased risk for IPV perpetration and/or victimization (Caetano et al., 2010; Caetano, Schafer, Clark, Cunradi, \& Raspberry, 2000; Cunradi, 2009, 2010; Cunradi et al., 2000; Cunradi, Caetano, \& Schafer, 2002b; Cunradi et al., 2011; Jain, Buka, Subramanian, \& Molnar, 2010; Livingston, 2010, 2011; McKinney, Caetano, Harris, et al., 2009). For example, McKinney, Caetano, Harris, et al. (2009) controlled for the influences of neighborhood poverty, ownership of occupied homes, and education (McKinney, Caetano, Ramisetty-Mikler, \& Nelson, 2009). Of those, increases in the percentage of living in poverty was significantly associated with increased odds of MFPV, and increases in the percentage of living in owner-occupied homes was also associated with increased odds of both MFPV and FMPV, whereas educational attainment was not found to be significantly associated with IPV. Similarly, Cunradi and colleagues (2011) controlled for neighborhood characteristics including race/ethnicity distributions, poverty, and unemployment. Higher percentages of Hispanics, those living below the $150 \%$ poverty line, and unemployed were all associated with increased IPV-related calls to police (Cunradi et al., 2011).

Finally, Caetano and colleagues (2010) examined several neighborhood characteristics and the pathways through which they influence MFPV and FMPV separately. They did not include alcohol outlet density as a measure, however neighborhood poverty was examined. A significant correlation was found between neighborhood poverty and MFPV and FMPV. In path analyses, however, neighborhood poverty was not a significant predictor of IPV either directly or indirectly.

These findings and others (Livingston, 2010, 2011) indicate that controlling for other neighborhood influences is critical when examining alcohol outlet density and IPV.

\section{THE CURRENT STUDY}

This study seeks to extend current IPV research by examining the associations among alcohol outlet density, drinking behaviors, and IPV victimization among young men in a large national representative sample. We test for the direct effect of alcohol outlet density on male IPV victimization and the indirect effect through the potential mediating variable of drinking patterns. We also control for the influences of social disorganization that may confound the association between outlet density and IPV and for individual level sociodemographic characteristics.

We consider two possible pathways through which alcohol outlet density may influence IPV victimization among males. The first pathway is that alcohol outlet density increases alcohol availability, and therefore, more alcohol is consumed by more people (Gruenewald, 2007; Gruenewald, Johnson, \& Treno, 2002; Gruenewald et al., 1996; Gruenewald \& Treno, 2000; Livingston, 2010), which leads to greater risk for IPV victimization. Thus, the influence of alcohol outlet density on IPV is indirect and mediated through the drinking behavior of the victim. To our knowledge, no previous studies examining outlet density and IPV have examined this possible mediating pathway among male victims of IPV.

The second path examined is a direct link from outlet density to IPV. Gruenewald (2007) proposes a social ecological theory that views alcohol outlets as the place where individual drinking behaviors interact with commercial and social markets for alcohol in a community setting. In other words, as outlet density changes, it affects the opportunities for one to drink, the context in which one prefers to drink, the contacts one has while drinking, and when and where one drinks (Gruenewald, 2007). This model suggests that a new alcohol outlet can increase IPV by increasing the number of customers of the outlet and increase the 
concentration of at-risk drinkers and drinking problems within a geographic location (Gruenewald, 2007). However, an increase in drinkers or drinking levels is not necessary to affect increases in IPV. (For a detailed review, please see Gruenewald, 2007.)

In this study, we test both paths of influence and hypothesized that there will be both direct and indirect effects of alcohol outlet density on IPV victimization among young men. Given that physical and sexual IPV may have different etiology and correlates, we distinguish between physical only IPV victimization and sexual only or sexual and physical IPV to examine if outlet density is differentially associated with the two IPV types. In the multiple variable models, we control for neighborhood-level potential confounds as well as individual characteristics such as age, race/ethnicity, marital status, and neglect and abuse experienced as a child. To highlight the role of alcohol outlet density in male victimization by a female partner, we examine only males for this study.

The specific aim of this study is to increase our understanding of the role of alcohol outlet density in male victims of IPV by a female partner. To do so, we test two potential pathways through which outlet density may influence male victimization. First, we test the direct effect of alcohol outlet density on IPV victimization and then test whether this effect is mediated by the drinking behaviors of the victim or the indirect effect.

\section{METHOD}

\section{Data and Sample}

Data used in analyses were from Wave III of the National Longitudinal Study of Adolescent Health (Add Health). Add Health is a prospective cohort study that has followed a nationally representative sample of adolescents in the United States into adulthood. At Wave III, the respondents were approximately 18-26 years old and were interviewed in 2001-2002 ( $N=$ $14,322)$. Add Health's original sample was drawn from 7th to 12th grade students on school enrollment rosters in 1994-1995. A sample of 80 high schools and 52 middle schools was selected with unequal probability of selection. Incorporating systematic sampling methods and implicit stratification into the study design ensured that selected schools were representative of U.S. schools with respect to region of country, urbanicity, school size, school type, and ethnicity. Add Health respondents provided written consent to be interviewed. Questionnaires were administered on laptop computers; computer-assisted selfinterviewing technology was used for sensitive topics such as sexual, substance use, and violence behaviors. Additional information about Add Health is available elsewhere (Harris et al., 2009). The Institutional Review Board (IRB) of the University of North Carolina at Chapel Hill approved Add Health study procedures. The IRB of the Pacific Institute for Research and Evaluation deemed protocols of the present authors' study exempt from IRB review.

For Wave III, Add Health researchers attempted to interview all original study participants living in the United States, including participants who are homeless and incarcerated. The response rate for Wave III was 77.4\% (Chantala, Kalsbeek, \& Andraca, 2003; Harris et al., 2009). In the interview, respondents were asked to list all romantic relationships and sexual relationships since the summer of 1995 and then were asked if they were currently involved with each partner. One current sexual or romantic relationship per respondent was examined for the present analyses. For respondents who reported more than one current relationship, we selected the relationship corresponding to the lowest relationship identification (ID) number to select the relationship in a generally random way. Respondents whose identified relationship was with a same-sex partner represented a very small percentage $(1.4 \%)$ and were excluded from analyses. The analysis sample was based on male respondents in Wave III who had at least one reported current relationship $(N=3,766)$, nonmissing data on IPV 
victimization $(N=3,501)$, nonmissing data on the alcohol use variable $(N=3,434)$, an index relationship partner not of the same sex $(N=3,364)$, and a nonmissing sampling weight (final $N=3,197$ ).

\section{Measures}

Intimate Partner Violence Victimization-Our measure of IPV victimization was based on the Wave III survey items, "How often in the past year has [PARTNER] threatened you with violence, pushed or shoved you, or thrown something at you that could hurt?" "How often in the past year has [PARTNER] slapped, hit, or kicked you?" and "How often in the past year has [PARTNER] insisted on or made you have sexual relations with [HIM/ HER] when you didn't want to?" Responses were dichotomized as no IPV in the past year (combining those who have never experienced FMPV and those who haven't experienced in the past year) versus happened one or more times in the past year. A three-category nominal variable was created to indicate type of IPV victimization experienced in the past year in the relationship: (0) physical IPV only, (1) either sexual IPV only or both physical and sexual IPV, and (2) no IPV (referent category).

Alcohol Outlet Density in Neighborhood: Data were obtained for number of alcohol outlets (establishments possessing on- and/or off-premise alcohol licenses) per square kilometer for the Wave III respondent communities. Alcohol outlet licensing data were gathered from individual states during 2006-2007, which was 5-6 years after the Wave III interview. However, alcohol outlet density in small geographic areas is considered to be relatively stable over time (Gruenewald \& Remer, 2006). Outlet addresses were geocoded to the census tract level. On-premise and off-premise outlet density measures were combined into a measure of total outlet density after preliminary analyses indicated similar association with IPV by type of outlet. The variable was Winsorized to address skewness, with values above or below three times the standard deviation recoded to be the value of three times the standard deviation.

A preliminary model indicated a curvilinear association between outlet density and experiencing physical versus no IPV victimization among males. Examination of victimization in relation to outlet density indicated increases in probability of physical IPV at around the 50th and 90th percentiles. Median total outlet density corresponded to 0.76 outlets per square kilometer, and the 90th percentile in density corresponded to 7.57 outlets per square kilometer. To facilitate interpretation, a three-category variable for neighborhood outlet density was created (and subsequently dummy coded), indicating low presence of alcohol outlets (less than one outlet per square kilometer; the referent category), medium outlet density (one to eight outlets), or high outlet density (more than eight outlets).

Alcohol Use: Various dimensions of alcohol use were incorporated into our alcohol use measure: ever drinking alcohol, ever drinking in the past 12 months, frequency and quantity of drinking in the past 12 months, heavy episodic (binge) drinking (four or more drinks on a single occasion in the past 2 weeks), and having ever been drunk in the past 12 months. The resulting six-category nominal variable was coded as follows: (a) lifetime abstainer or former (but not current) drinker, (b) light drinker, (c) moderate drinker, (d) infrequent heavy drinker, (e) occasional heavy drinker, and (f) frequent heavy drinker. Category descriptions are provided in Table 1.

Control Variables: Age was measured in years. Race/ethnicity, based on respondent selfreport, was Hispanic (of any race) and non-Hispanic categories of White, Black, Asian or Pacific Islander, and American Indian or Native American. For multiracial participants, the category the respondent selected as best describing his racial background was used. Marital 
status of the reference relationship was indicated by the categories never married or ever lived with the partner (referent group), lived with the partner but never married her, or ever married the partner. Three variables indicated the respondent's recollection of a parent or other adult caregiver's behavior before he was in sixth grade pertaining to (a) neglect (left the respondent home alone when an adult should have been present or did not take care of the respondent's basic needs); (b) "slapped, hit, or kicked" the respondent; and (c) sexually abused the respondent defined as the adult touching the child in a sexual way, forcing the child to touch the adult in a sexual way, or forcing the child to have sexual relations. Each maltreatment measure was dichotomized (the event occurred or not).

Based on previous research, several neighborhood-level sociodemographic characteristics were included as control variables reflecting social disorganization in the community (Caetano et al., 2010; Cunradi, 2007, 2009; Madkour, Martin, Halpern, \& Schoenbach, 2010). Based on tract-level census data (Census of Population and Housing, 2000: Summary File 3; Swisher, 2008), the measures pertain to (a) poverty (an index of the average of the standardized estimates for the unemployment rate, proportion of persons below the poverty level, and proportion of families with a child in a female-headed household; Cronbach's alpha $=.72$ ), (b) transience (an index of the average of the standardized estimates for the proportion of the population who had moved in the past 5 years and the proportion of occupied units that were renter occupied; Cronbach's alpha $=.82$ ), (c) proportion of residents who were foreign born, and (d) proportion of vacant housing units (Swisher, 2008).

\section{Data Analyses}

Three multinomial logistic regressions were then carried out using IPV victimization as the dependent variable (referent category was not having experienced IPV victimization in the relationship). In Model 1, only alcohol outlet density and alcohol use predictors were examined. Model 2 included alcohol outlet density and alcohol use, plus individual-level control variables of respondent's age, race/ethnicity, marital status, and reports of having been neglected, sexually abused, or physically abused as a child. Model 3 included all of the variables used in Models 1 and 2 but also included community-level control variables of neighborhood poverty, transience, foreign-born residents, and housing vacancy. Multilevel modeling was not used for community-level variables because there were few census tracts with more than one respondent and data were not sufficiently nested (Cubbin, Brindis, Jain, Santelli, \& Braveman, 2010; Cubbin, Santelli, Brindis, \& Braveman, 2005). Lastly, models in which alcohol outlet density was found to be a significant predictor of IPV victimization were further examined using structural equation modeling to test for alcohol use as a mediator of the relationship between outlet density and IPV.

Poststratification sampling weights were incorporated in analyses to yield estimates representative of the national population. Data analyses were conducted using SAS (version 9.13, SAS Institute Inc, Cary, NC), MPlus (version 6, Muthén \& Muthén, Los Angeles, CA), and Stata (version SE 11.1, StataCorp, College Station, TX). Procedures for survey data analysis in Mplus and Stata were used to account for Add Health's complex sampling design, which had strata represented by regions and cluster by school at study enrollment, in the regression models. Weighted percentages and unweighted sample sizes are reported in the results.

\section{RESULTS}

About $22 \%$ of the young men in our analysis sample reported having been a victim of IPV in the past year in their current relationship. Reporting having experienced physical IPV only (15.7\%) was more common than reporting sexual IPV only or physical and sexual IPV 
(6.4\%). Although abstainers (either lifetime abstainers or former drinkers) were a sizeable group (22.6\%), nearly two thirds of the sample (63.1\%) could be classified as being in one of the three heavy drinker categories (infrequent, occasional, or frequent heavy drinkers). The modal alcohol use category among the young men was occasional heavy drinking $(35.2 \%)$. The IPV, drinking behavior, and sociodemographic characteristics of the sample are shown in Table 2.

\section{Multivariable Models}

Results from the three multivariate multinomial logistic regression models are presented in Table 3. Alcohol outlet density did not have a statistically significant association with IPV victimization among young men in the model that included only outlet density and alcohol use (Model 1), nor in the model that controlled for individual-level characteristics (Model 2). In Model 3, which controlled for community-level and individual-level characteristics, respondents in high alcohol outlet density neighborhoods had significantly increased odds of experiencing physical IPV compared to individuals in low outlet density neighborhoods ( $O R$ $=2.07 ; 95 \%$ confidence interval $[\mathrm{CI}]=1.19-3.63)$.

Each of the three heavy drinking groups (compared to abstention) was positively associated with physical IPV victimization in Model 2 and in Model 3. Frequent heavy drinkers also had increased odds of experiencing sexual only or physical and sexual IPV in each of the three models.

Hispanic men had greater odds of physical IPV victimization than non-Hispanic White men; Asians had greater odds of sexual only or physical and sexual victimization. Black and Native American men had greater odds of both types of victimization. Young men cohabiting with their partner had nearly three times higher odds of experiencing physical IPV than respondents who were neither cohabiting with nor married to their partner. Similarly, odds of physical IPV were more than four times larger among young men married to their partner. Of the neighborhood control variables, only transience in one's neighborhood was significantly associated with IPV.

\section{Testing of Indirect Effects}

Because high alcohol outlet density was found to be significantly associated with physical IPV victimization in Model 3, analyses were conducted to assess if alcohol use operated as a mediator between outlet density and IPV in that model. Results did not indicate statistically significant indirect effects from high outlet density to physical IPV for any of the drinking categories (regression coefficients ranged from -0.09 to -0.01 , all $n s$ [nonsignificant]), suggesting that alcohol use was not a mediator between outlet density and physical IPV.

\section{DISCUSSION}

This is the first study, to our knowledge, to examine the role of alcohol outlet density on male IPV victimization by a female partner and to examine the potential mediating effect of drinking behavior on the influence of alcohol outlet density on IPV victimization among males. Our hypothesis that males living in areas characterized by high alcohol outlet density would be more likely to be victims of IPV perpetrated by their female partners was confirmed. Two pathways through which density could affect IPV victimization were tested. The first was a direct association between outlet density and IPV victimization. We also examined whether outlet density had an indirect effect on IPV victimization through changing alcohol consumption patterns. In our final adjusted model, which included tract level measures of social disorganization, high alcohol outlet density was associated with twice the odds of male physical IPV victimization compared to low outlet density. Our 
findings are consistent with other studies that have found a direct association between outlet density and IPV even after controlling for the influence of drinking behaviors and other neighborhood-level risk factors (Cunradi et al., 2011; Livingston, 2010, 2011; McKinney, Caetano, Harris, et al., 2009). Furthermore, our findings are consistent with the predictions that Gruenewald's (2007) social ecological theory of alcohol outlets and alcohol-related problems would suggest. The influence of alcohol outlet density on who is drinking, the context in which the drinking occurs, the contacts one has while drinking, and the locations and times of use has the ability to aggravate or mitigate problems with alcohol use, including IPV victimization among males (Gruenewald, 2007).

Contrary to our expectation, however, we did not find any evidence to support the possibility of mediation of the relationship between outlet density and IPV by drinking behavior. Our mediation hypothesis posited that increased alcohol availability should lead to increased consumption of alcohol, which in turn should lead to increases in IPV occurrence. It was surprising to find no evidence for mediation, given evidence indicating that high alcohol density is linked to greater alcohol consumption and that higher alcohol consumption is associated with increased IPV.

Nevertheless, alcohol consumption was a significant predictor of IPV. Heavy drinking patterns, whether infrequent, occasional, or frequent, were all associated with increased odds of experiencing physical only IPV victimization after controlling for alcohol outlet density as well as all other individual- and neighborhood-level variables in the models. Odds of experiencing physical IPV were most elevated (about 2.5 times greater) among men who were frequent heavy drinkers. These findings are consistent with another study using national data that examined married and cohabiting couples and found greatest odds of mutual physical IPV experienced by men characterized as frequent heavy drinkers (Cunradi, 2007).

Not surprisingly, one important risk factor for physical only IPV victimization to note was marital status. In comparison to neither being married to nor cohabitating with one's partner, cohabitating with the partner was associated with 2.9 times greater odds of a man experiencing physical only IPV in the final adjusted model, and being married was associated with more than four times greater odds. Behavioral or psychological partner dynamics that vary by type of relationship or selection effects of who chooses to cohabit and who chooses to marry may account for differences in men experiencing IPV by their female partner.

In contrast to previous research, we did not find neighborhood-level indicators of social disorganization to be overly associated with IPV victimization among males (Caetano et al., 2010; Cunradi, 2007, 2009, 2010; Cunradi et al., 2000; Cunradi et al., 2011; Livingston, 2010, 2011; McKinney, Caetano, Harris, et al., 2009). Interestingly, neighborhood transience, an index of the proportion of occupied units that were renter occupied and the proportion of the population that had moved in the past 5 years, was the only significant indicator. Nevertheless, it was negatively associated with physical only IPV while it was positively associated with sexual only or sexual and physical IPV. However, the ORs, although statistically significant, are almost marginal so to what extent we would want to place emphasis on this association is uncertain.

Given the paucity of research, particularly about sexual IPV victimization among males, this study contributes important information on this topic. The proportion of young men who reported having experienced any sexual violence in the past year perpetrated by their female partner, 6\%, is not large, but neither is it negligible. As was true of physical IPV, frequent heavy drinking by the young men in the sample was associated with increased odds of being 
a victim of sexual only or both sexual and physical violence from their partner. However, alcohol outlet density was not found to be associated with IPV victimization among men when the IPV included sexual violence, suggesting that sexual victimization among men is likely to have a different etiology than physical IPV. Whether frequent heavy drinking makes males more vulnerable to experiencing sexual IPV by a female partner in the same way that it makes females more vulnerable to experiencing sexual IPV is unclear. Further research examining if there are potentially modifiable environmental factors other than alcohol outlet density that may contribute to sexual IPV victimization among men is needed in addition to research studying whether alcohol consumption works through similar pathways to affect IPV risk among males and females.

\section{Study Limitations}

Our findings should be interpreted within the context of the study limitations. First, this is a cross-sectional study, and therefore, conclusions about the directionality of associations cannot be made. Furthermore, Add Health does not ask about alcohol use by either the perpetrator or victim at the time of the incident. We rely on the patterns of drinking that respondents report typically engaging in as a proxy. Thus, although an association between outlet density and IPV victimization exists in our sample, it does not necessarily mean that alcohol use was involved during a specific IPV event. Another limitation of the data and variables used for present analyses is the lack of alcohol use measures for the respondents' partners. A more complete conceptual model would include alcohol use by both the respondent and his partner, as previous research indicates that use by both persons increases the likelihood of IPV (McKinney et al., 2010). The impact of this limitation is that the direct effect of outlet density on the risk of IPV victimization among young men that we found could be due in part to the influence of the partner's alcohol use, which is not measured. Additionally, some of the nonsignificant results found from the multinomial logistic regressions (e.g., the association between being Hispanic and sexual IPV perpetration and ever married to a partner and sexual IPV) may have been the result of small sample sizes, although the weighting of data should have compensated somewhat for this limitation. Finally, we only examine male victims of IPV by a female partner. We did not discriminate between male victims only and male victims and perpetrators, although outlet density and consumption may differ in their association with IPV. The decision was made to examine only male victims because this subgroup is frequently marginalized in the IPV research literature. Yet, studies using the Conflict Tactics Scale to assess IPV perpetration and victimization have found that females report more IPV perpetration against their male partners than males report perpetrating against female partners and males report higher victimization than females do (Archer, 2000; Herrera, Wiersma, \& Cleveland, 2008). For example, Caetano, Ramisetty-Mikler, and Field (2005) found in their examination of IPV among a national, multistage household probability sample of White, Black, and Hispanic couples that exclusive FMPV was actually more common than exclusive MFPV (Caetano, Ramisetty-Mikler, et al., 2005). Likewise, Melander and colleagues (2010), using a national representative data set of young adults, found a similar pattern.

\section{CONCLUSIONS}

This study is the first to our knowledge to explore the potential mediating effects of alcohol consumption on the relationship between alcohol outlet density and IPV. In answer to the call for more research focused on understanding the mechanisms through which alcohol outlet density influences IPV, this study examined two possible mechanisms of association. The findings suggest that increases in alcohol outlet density may alter the routine drinking habits of young men in such a way as to increase the risk of being physically victimized by a female partner. Continued exploration of the relationship between environmental level 
indicators is encouraged because findings are contradictory on how much influence the neighborhood characteristics have in influencing IPV. Greater understanding of how alcohol outlet density interacts with and/or or predicts measures of social disorganization is also needed.

Examining only male victims provided a basic understanding of the role of outlet density in IPV among this often overlooked subpopulation. It is important that prevention strategies take into consideration that environmental risk factors differ for males and females as well as between perpetrators and victims of IPV (Waller et al., 2012).

Together with the present findings, there is a growing body of evidence that limiting outlet density may greatly reduce numerous alcohol-related outcomes, including IPV. This understanding can inform local land management and zoning ordinances, public policy, as well as prevention programs (Campbell et al., 2009; Livingston, Chikritzhs, \& Room, 2007). Although broad-reaching environmental prevention is ideal, direct prevention providers also should consider how they might influence not only individual alcohol consumption behaviors but also where one drinks and with whom one drinks to reduce individual IPV risk.

\section{Acknowledgments}

Funding for this study is from the National Institute for Alcohol and Alcohol Abuse (R03AA016809, MWW, principal investigator). This research uses data from Add Health, a program project directed by Kathleen Mullan Harris and designed by J. Richard Udry, Peter S. Bearman, and Kathleen Mullan Harris at the University of North Carolina at Chapel Hill and funded by grant P01-HD31921 from the Eunice Kennedy Shriver National Institute of Child Health and Human Development, with cooperative funding from 23 other federal agencies and foundations. Special acknowledgment is due to Ronald R. Rindfuss and Barbara Entwisle for assistance in the original design. Information on how to obtain the Add Health data files is available on the Add Health Website (http:// www.cpc.unc.edu/addhealth). No direct support was received from grant P01-HD31921 for this analysis.

\section{References}

Archer J. Sex differences in aggression between heterosexual partners: A meta-analytic review. Psychological Bulletin. 2000; 126(5):651-680. [PubMed: 10989615]

Caetano R, Field CA, Ramisetty-Mikler S, McGrath C. The 5-year course of intimate partner violence among White, Black, and Hispanic couples in the United States. Journal of Interpersonal Violence. 2005; 20(9):1039-1057. [PubMed: 16051726]

Caetano R, Ramisetty-Mikler S, Field CA. Unidirectional and bidirectional intimate partner violence among White, Black, and Hispanic couples in the United States. Violence and Victims. 2005; 20(4): 393-406. [PubMed: 16250407]

Caetano R, Ramisetty-Mikler S, Harris TR. Drinking, alcohol problems and intimate partner violence among white and Hispanic couples in the U.S.: Longitudinal associations. Journal of Family Violence. 2008; 23:37-45.

Caetano R, Ramisetty-Mikler S, Harris TR. Neighborhood characteristics as predictors of male to female and female to male partner violence. Journal of Interpersonal Violence. 2010; 25(11):19892009.

Caetano R, Schafer J, Clark CL, Cunradi CB, Raspberry K. Intimate partner violence, acculturation, and alcohol consumption among Hispanic couples in the United States. Journal of Interpersonal Violence. 2000; 15(1):30-45.

Caetano R, Vaeth P, Ramisetty-Mikler S. Intimate partner violence victim and perpetrator characteristics among couples in the United States. Journal of Family Violence. 2008; 23(6):507518 .

Campbell CA, Hahn RA, Elder R, Brewer R, Chattopadhyay S, Fielding J, et al. The effectiveness of limiting alcohol outlet density as a means of reducing excessive alcohol consumption and alcoholrelated harms. American Journal of Preventive Medicine. 2009; 37(6):556-569. [PubMed: 19944925] 
Chan KL, Straus MA, Brownridge DA, Tiwari A, Leung WC. Prevalence of data partner violence and suicidal ideation among male and female university students worldwide. Journal of Midwifery and Women's Health. 2008; 53:529-537.

Chantala, K.; Kalsbeek, WD.; Andraca, E. Non-response in Wave III of the Add Health study. 2003. Retrieved May 14, 2006, from http://www.cpc.unc.edu/projects/addhealth/files/analyze.pdf

Chen M, Grube JW, Gruenewald PJ. Community alcohol outlet density and underage drinking. Addiction. 2010; 105(2):270-278. [PubMed: 20078485]

Coker AL, Davis KE, Arias I, Desai S, Sanderson M, Brandt HM, et al. Physical and mental health effects of intermate partner violence among men and women. Journal of Preventive Medicine. 2002; 23:260-268.

Coker AL, Weston RW, Creson DL, Justice B, Blakeney P. PTSD symptoms among men and women survivors of intimate partner violence: The role of risk and protective factors. Violence and Victims. 2005; 20:625-643. [PubMed: 16468442]

Cubbin C, Brindis CD, Jain S, Santelli J, Braveman P. Neighborhood poverty, aspirations and expectations, and initiation of sex. Journal of Adolescent Health. 2010; 47(4):399-406. http:// dx.doi.org/10.1016/j.jadohealth.2010.02.010. [PubMed: 20864010]

Cubbin C, Santelli J, Brindis CD, Braveman P. Neighborhood context and sexual behaviors among adolescents: findings from the national longitudinal study of adolescent health. Perspective on Sexual and Reproductive Health. 2005; 37(3):125-134.

Cunradi CB. Drinking level, neighborhood social disorder, and mutual intimate partner violence. Alcoholism: Clinical and Experimental Research. 2007; 31(6):1012-1019.

Cunradi CB. Intimate partner violence among Hispanic men and women: The role of drinking, neighborhood disorder, and acculturation-related factors. Violence and Victims. 2009; 24(1):8397. [PubMed: 19297887]

Cunradi CB. Neighborhoods, alcohol outlets and intimate partner violence: Addressing research gaps in explanatory mechanisms. International Journal of Environmental Research and Public Health. 2010; 7(3):799-813. http://dx.doi.org/10.3390/ijerph7030799. [PubMed: 20617004]

Cunradi CB, Caetano R, Clark CL, Schafer J. Alcohol-related problems and intimate partner violence among white, black, and Hispanic couples in the U.S. Alcoholism, Clinical and Experimental Research. 1999; 23(9):1492-1501.

Cunradi CB, Caetano R, Clark C, Schafer J. Neighborhood poverty as a predictor of intimate partner violence among White, Black, and Hispanic couples in the United States: A multilevel analysis. Annals of Epidemiology. 2000; 10(5):297-308. [PubMed: 10942878]

Cunradi CB, Caetano R, Schafer J. Alcohol-related problems, drug use, and male intimate partner violence severity among US couples. Alcoholism, Clinical and Experimental Research. 2002a; 26(4):493-500.

Cunradi CB, Caetano R, Schafer J. Socioeconomic predictors of intimate partner violence among white, black, and Hispanic couples in the United States. Journal of Family Violence. 2002b; 17(4): 377-389.

Cunradi CB, Mair C, Ponicki W, Remer L. Alcohol outlets, neighborhood characteristics, and intimate partner violence: Ecological analysis of a California City. Journal of Urban Health: Bulletin of the New York Academy of Medicine. 2011; 88(2):191-200. http://dx.doi.org/10.1007/ s11524-011-9549-6. [PubMed: 21347557]

Fisher, BS.; Cullen, FT.; Turner, MG. The sexual victimization of college women. Washington, DC: National Institute of Justice, Bureau of Justice Statistics; 2000.

Fletcher J. The effects of intimate partner violence on health in young adulthood in the United States. Social Science and Medicine. 2010; 70:130-135. [PubMed: 19819603]

Foran HM, O'Leary KD. Alcohol and intimate partner violence: a meta-analytic review. Clinical Psychology Review. 2008; 28(7):1222-1234. [PubMed: 18550239]

Freisthler B, Midanik LT, Gruenewald PJ. Alcohol outlets and child physical abuse and neglect: Applying routine activities theory to the study of child maltreatment. Journal of Studies on Alcohol. 2004; 65(5):586-592. [PubMed: 15536767]

Gorman DM, Labouvie EW, Speer PW, Subaiya AP. Alcohol availability and domestic violence. American Journal of Drug and Alcohol Abuse. 1998; 24(4):661-673. [PubMed: 9849776] 
Graham K, Bernards S, Wilsnack SC, Gmel G. Alcohol may not cause partner violence but it seems to make it worse: A cross national comparison of the relationship between alcohol and severity of partner violence. Journal of Interpersonal Violence. 2011; 26(8):1503-1523. [PubMed: 20522883]

Gruenewald PJ. The spatial ecology of alcohol problems: Niche theory and assortative drinking. Addiction. 2007; 102:870-878. [PubMed: 17523980]

Gruenewald PJ, Freisthler B, Remer L, LaScala EA, Treno A. Ecological models of alcohol outlets and violent assaults: Crime potentials and geospatial analysis. Addiction. 2006; 101(5):666-677. http:// dx.doi.org/10.1111/j.1360-0443.2006.01405.x. [PubMed: 16669900]

Gruenewald PJ, Johnson FW, Treno AJ. Outlets, drinking and driving: A multilevel analysis of availability. Journal of Studies on Alcohol. 2002; 63(4):460-468. [PubMed: 12160105]

Gruenewald PJ, Millar AB, Treno AJ, Yang Z, Ponicki WR, Roeper P. The geography of availability and driving after drinking. Addiction. 1996; 91(7):976-983.

Gruenewald PJ, Remer L. Changes in outlet densities affect violence rates. Alcoholism, Clinical and Experimental Research. 2006; 30(7):1184-1193.

Gruenewald PJ, Remer L, Lipton R. Evaluating the alcohol environment: community geography and alcohol problems. Alcohol Research \& Health. 2002; 26(1):42-48. [PubMed: 12154650]

Gruenewald PJ, Treno AJ. Local and global alcohol supply: Economic and geographic models of community systems. Addiction. 2000; 95(Suppl 4):S537-S549. [PubMed: 11218350]

Harris, KM.; Halpern, CT.; Whitsel, E.; Hussey, J.; Tabor, J.; Entzel, P., et al. The National Longitudinal Study of Adolescent Health: Research design. Chapel Hill, NC: Carolina Population Center, University of North Carolina; 2009. Retrieved May 7, 2010, from http://www.cpc.unc.edu/ projects/addhealth/design

Herrera VM, Wiersma JD, Cleveland HH. The influence of individual and partner characteristics on the perpetration of intimate partner violence in young adult relationships. Journal of Youth and Adolescence. 2008; 37(3):284-296. http://dx.doi.org/10.1007/s10964-007-9249-4.

Hines DA, Brown J, Dunning E. Characteristics of callers to the domestic abuse hotline for men. Journal of Family Violence. 2007; 22:63-72.

Hines DA, Malley-Morrison K. Psychological effects of partner abuse against men: A neglected research area. Psychology of Men \& Masculinity. 2001; 2:75-85.

Jain S, Buka SL, Subramanian SV, Molnar BE. Neighborhood predictors of dating violence victimization and perpetration in young adulthood: A multilevel study. American Journal of Public Health. 2010; 100(9):1737-1744. http://dx.doi.org/10.2105/ajph.2009.169730. [PubMed: 20634470]

Leonard KE. Alcohol and intimate partner violence: When can we say that heavy drinking is a contributing cause of violence? Addiction. 2005; 100(4):422-425. [PubMed: 15784050]

Lipsky S, Caetano R, Field CA, Bazargan S. The role of alcohol use and depression in intimate partner violence among black and Hispanic patients in an urban emergency department. The American Journal of Drug and Alcohol Abuse. 2005; 31(2):225-242. [PubMed: 15912713]

Lipsky S, Caetano R, Field CA, Larkin GL. Is there a relationship between victim and partner alcohol use during an intimate partner violence event? Findings from an urban emergency department study of abused women. Journal of Studies on Alcohol. 2005; 66(3):407-412. [PubMed: 16047531]

Livingston M. Alcohol outlet density and assault: A spatial analysis. Addiction. 2008a; 103:619-628. [PubMed: 18339106]

Livingston M. A longitudinal analysis of alcohol outlet density and assault. Alcoholism, Clinical and Experimental Research. 2008b; 32(6):1074-1079.

Livingston M. The ecology of domestic violence: The role of alcohol outlet density. Geospatial Health. 2010; 5(1):139-149. [PubMed: 21080328]

Livingston M. A longitudinal analysis of alcohol outlet density and domestic violence. Addiction. 2011; 106(5):919-925. http:/dx.doi.org/10.1111/j.1360-0443.2010.03333.x. [PubMed: 21205052]

Livingston M, Chikritzhs T, Room R. Changing the density of alcohol outlets to reduce alcohol-related problems. Drug and Alcohol Review. 2007; 26:557-566. [PubMed: 17701520] 
Madkour AS, Martin SL, Halpern CT, Schoenbach VJ. Area disadvantage and intimate partner homicide: An ecological analysis of North Carolina counties, 2004-2006. Violence and Victims. 2010; 25(3):363-377. [PubMed: 20565007]

McKinney CM, Caetano R, Harris TR, Ebama MS. Alcohol availability and intimate partner violence among US couples. Alcoholism, Clinical And Experimental Research. 2009; 33(1):169-176.

McKinney CM, Caetano R, Ramisetty-Mikler S, Nelson S. Childhood family violence and perpetration and victimization of intimate partner violence: Findings from a national population-based study of couples. Annals of Epidemiology. 2009; 19(1):25-32. [PubMed: 18835525]

McKinney CM, Caetano R, Rodriguez LA, Okoro N. Does alcohol involvement increase the severity of intimate partner violence? Alcoholism, Clinical and Experimental Research. 2010; 34(4):655658. http://dx.doi.org/10.1111/j.1530-0277.2009.01134.x.

Melander LA, Noel H, Tyler KA. Bidiration, unidirectional, and nonviolence: A comparison of the predictors among partnered young adults. Violence and Victims. 2010; 25(5):617-630. [PubMed: 21061868]

Parkhill MR, Abbey A. Does alcohol contribute to the confluence model of sexual assault perpetration? Journal of Social and Clinical Psychology. 2008; 27(6):529-554.

Peek-Asa C, Zwerling C, Young T, Stromquist AM, Burmeister LF, Merchant JA. A population based study of reporting patterns and characteristics of men who abuse their female partners. Injury Prevention. 2005; 11(3):180-185. [PubMed: 15933412]

Randle AA, Graham CA. A review of the evidence on the effects of intimate partner violence on men. Psychology of Men \& Masculinity. 2011; 12(2):97-111. http://dx.doi.org/10.1037/a0021944.

Reed E, Amaro H, Matsumoto A, Kaysen D. The relation between interpersonal violence and substance use among a sample of university students: examination of the role of victim and perpetrator substance use. Addictive Behaviors. 2009; 34(3):316-318. [PubMed: 19028021]

Scribner RA, Mason KE, Simonsen NR, Theall K, Chotalia J, Johnson S, et al. An ecological analysis of alcohol-outlet density and campus-reported violence at 32 US colleges. Journal of Studies on Alcohol and Drugs. 2010; 71(2):184-191. [PubMed: 20230715]

Scribner RA, Mason K, Theall K, Simonsen N, Schneider S, Towvim L, et al. The contextual role of alcohol outlet density in college drinking. Journal of Studies on Alcohol and Drugs. 2008; 69:112120. [PubMed: 18080071]

Swisher, RR. Wave III contextual database codebook, part 1. Chapel Hill, NC: University of North Carolina, Carolina Population Center; 2008.

Thompson MP, Kingree JB. The roles of victim and perpetrator alcohol use in intimate partner violence outcomes. Journal of Interpersonal Violence. 2006; 21(2):163-177. [PubMed: 16368759]

Treno AJ, Gruenewald PJ, Remer LG, Johnson F, LaScala EA. Examining multilevel relationships between bars, hostility and aggression: Social selection and social influence. Addiction. 2008; 103(1):66-77. [PubMed: 18028523]

Treno AJ, Ponicki WR, Remer LG, Gruenewald PJ. Alcohol outlets, youth drinking, and self-reported ease of access to alcohol: A constraints and opportunities approach. Alcoholism, Clinical And Experimental Research. 2008; 32(8):1372-1379.

Waller MW, Iritani BJ, Christ SL, Clark HK, Moracco KE, Halpern CT, Flewelling RL. Relationships among alcohol outlet density, alcohol use, and intimate partner violence victimization among young women in the United States. Journal of Interpersonal Violence. 2012; 27(10):2062-2086. [PubMed: 22204949] 
TABLE 1

\section{Alcohol Use Categories}

\begin{tabular}{ll}
\hline Category & Description \\
\hline $\begin{array}{l}\text { 1. Lifetime abstainers or ex- } \\
\text { drinkers }\end{array}$ & $\begin{array}{l}\text { Lifetime abstainers were respondents who reported never drinking alcohol during adolescence, never drinking } \\
\text { alcohol as an adult, and not drinking in the past } 12 \text { months. Ex-drinkers were respondents who at Wave I and/ } \\
\text { or Wave III indicated they drank alcohol but had not drank any alcohol in the past } 12 \text { months. }\end{array}$ \\
$\begin{array}{l}\text { 2. Light drinkers } \\
\text { Reported drinking in the past } 12 \text { months but having only one or two drinks at a time and not having been drunk } \\
\text { in the past year or engaging in heavy episodic drinking in the past } 2 \text { weeks. }\end{array}$ \\
$\begin{array}{l}\text { 3. Moderate drinkers } \\
\text { drunk in the past year nor engaging in heavy episodic drinking in the past } 2 \text { weeks. }\end{array}$ \\
$\begin{array}{l}\text { 4. Infrequent heavy drinkers } \\
\text { and/or heavy episodic drinking in the past } 2 \text { weeks. }\end{array}$ \\
5. Occasional heavy drinkers \\
$\begin{array}{l}\text { Reported drinking more frequently (2 or } 3 \text { days a month up to } 1 \text { to } 2 \text { days a week) over the past } 12 \text { months and } \\
\text { having been drunk in the past year and/or heavy episodic drinking in the past } 2 \text { weeks. }\end{array}$ \\
$\begin{array}{l}\text { Reported drinking frequently (3-7 days a week on average) over the past } 12 \text { months and having been drunk in } \\
\text { the past year and/or heavy episodic drinking in the past } 2 \text { weeks. }\end{array}$
\end{tabular}

Violence Vict. Author manuscript; available in PMC 2013 January 01. 
TABLE 2

Characteristics of Analysis Sample of Young Men in the National Longitudinal Study of Adolescent Health, 2001-2002 $(N=3,197)$

\begin{tabular}{|c|c|c|}
\hline Characteristic & No. & Weighted \% or Mean (SE) \\
\hline \multicolumn{3}{|l|}{ Victim of intimate partner violence } \\
\hline No IPV victimization & 2,491 & 77.88 \\
\hline Physical IPV only & 483 & 15.73 \\
\hline Sexual IPV only or physical and sexual IPV & 223 & 6.39 \\
\hline \multicolumn{3}{|l|}{ Alcohol use } \\
\hline Lifetime abstainer or ex-drinker & 726 & 22.59 \\
\hline Light drinker & 299 & 8.18 \\
\hline Moderate drinker & 195 & 6.11 \\
\hline Infrequent heavy drinker & 455 & 14.05 \\
\hline Occasional heavy drinker & 1,134 & 35.16 \\
\hline Frequent heavy drinker & 388 & 13.92 \\
\hline \multicolumn{3}{|l|}{ Alcohol outlet density in neighborhood (outlets per square kilometer) } \\
\hline Less than 1 outlet & 1,521 & 55.18 \\
\hline $1-8$ outlets & 1,069 & 35.70 \\
\hline More than 8 outlets & 359 & 9.11 \\
\hline \multicolumn{3}{|l|}{ Age in years } \\
\hline $18-20$ & 591 & 24.40 \\
\hline 21 & 491 & 16.59 \\
\hline 22 & 630 & 16.16 \\
\hline 23 & 647 & 16.13 \\
\hline $24-27$ & 838 & 26.72 \\
\hline \multicolumn{3}{|l|}{ Race/ethnicity } \\
\hline Hispanic & 573 & 12.56 \\
\hline Non-Hispanic White & 1,809 & 68.55 \\
\hline Non-Hispanic Black & 572 & 14.63 \\
\hline Non-Hispanic Asian & 201 & 3.04 \\
\hline Non-Hispanic American Indian & 42 & 1.21 \\
\hline \multicolumn{3}{|l|}{ Marital status } \\
\hline Never married or lived with his partner & 1460 & 46.22 \\
\hline Ever lived with his partner but never married & 948 & 31.61 \\
\hline Ever married to his partner & 734 & 22.17 \\
\hline Neglected as a child (percent yes) & 1386 & 45.07 \\
\hline Sexually abused as a child (percent yes) & 124 & 4.42 \\
\hline Physically abused as a child (percent yes) & 939 & 29.29 \\
\hline \multicolumn{3}{|l|}{ Neighborhood characteristics control variables } \\
\hline Proportion of population in poverty, standardized (mean $[S E]$ ) & & $-0.59(0.91)$ \\
\hline Transience index, standardized (mean $[S E]$ ) & & $-0.33(1.05)$ \\
\hline Proportion of foreign-born population (mean $[S E]$ ) & & $0.10(0.01)$ \\
\hline
\end{tabular}




\begin{tabular}{lcc}
\hline Characteristic & No. & Weighted \% or Mean $(S E)$ \\
\hline Proportion of vacant housing units (mean $[S E])$ & $0.08(0.00)$ \\
\hline
\end{tabular}

Note. Based on the sample of young adult men at Wave III in the national probability sample with at least one reported current relationship, with nonmissing data on this study's intimate partner violence victimization and alcohol use variables, and whose index relationship was not a same-sex relationship.

$S E=$ standard error; IPV = intimate partner violence. 


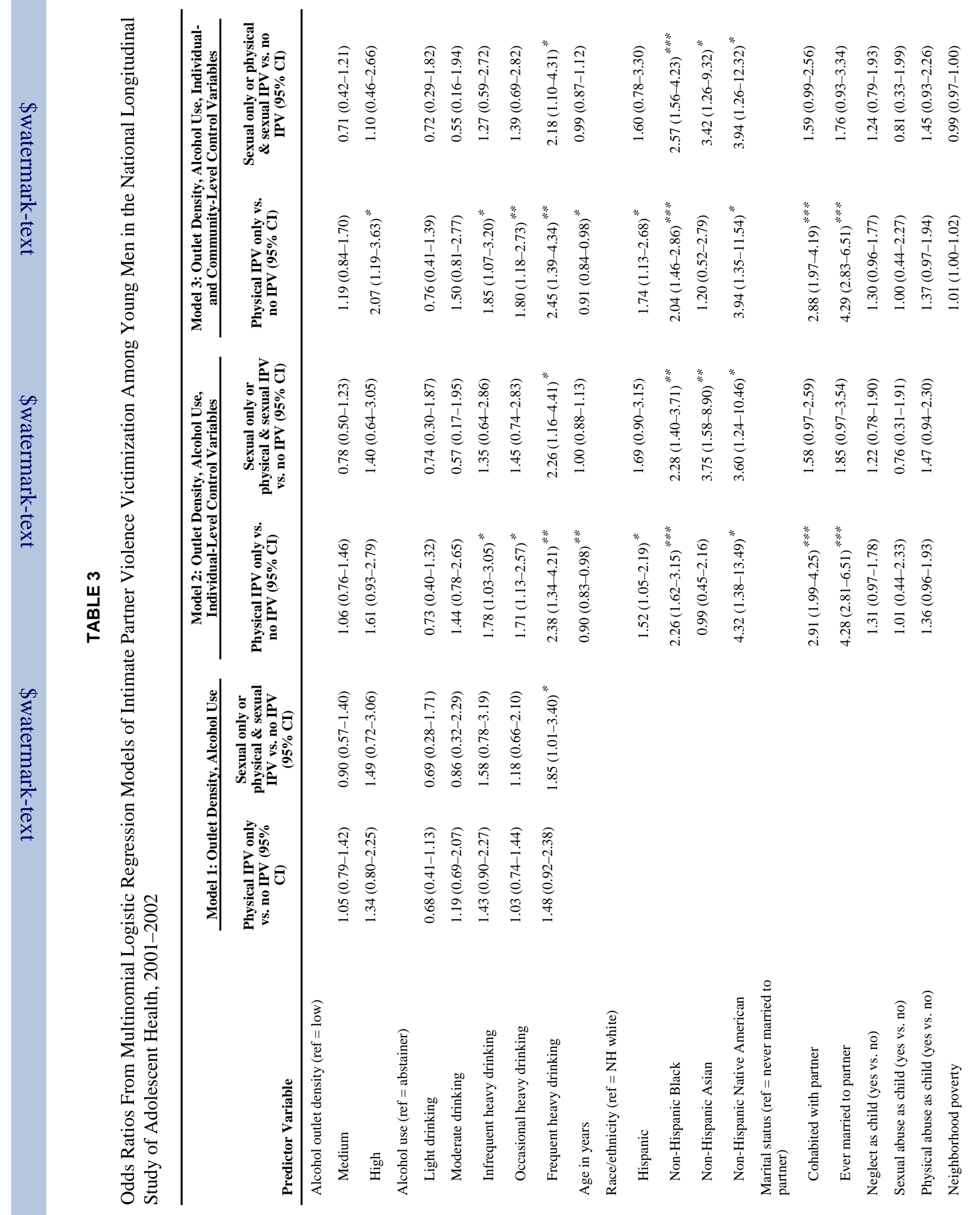




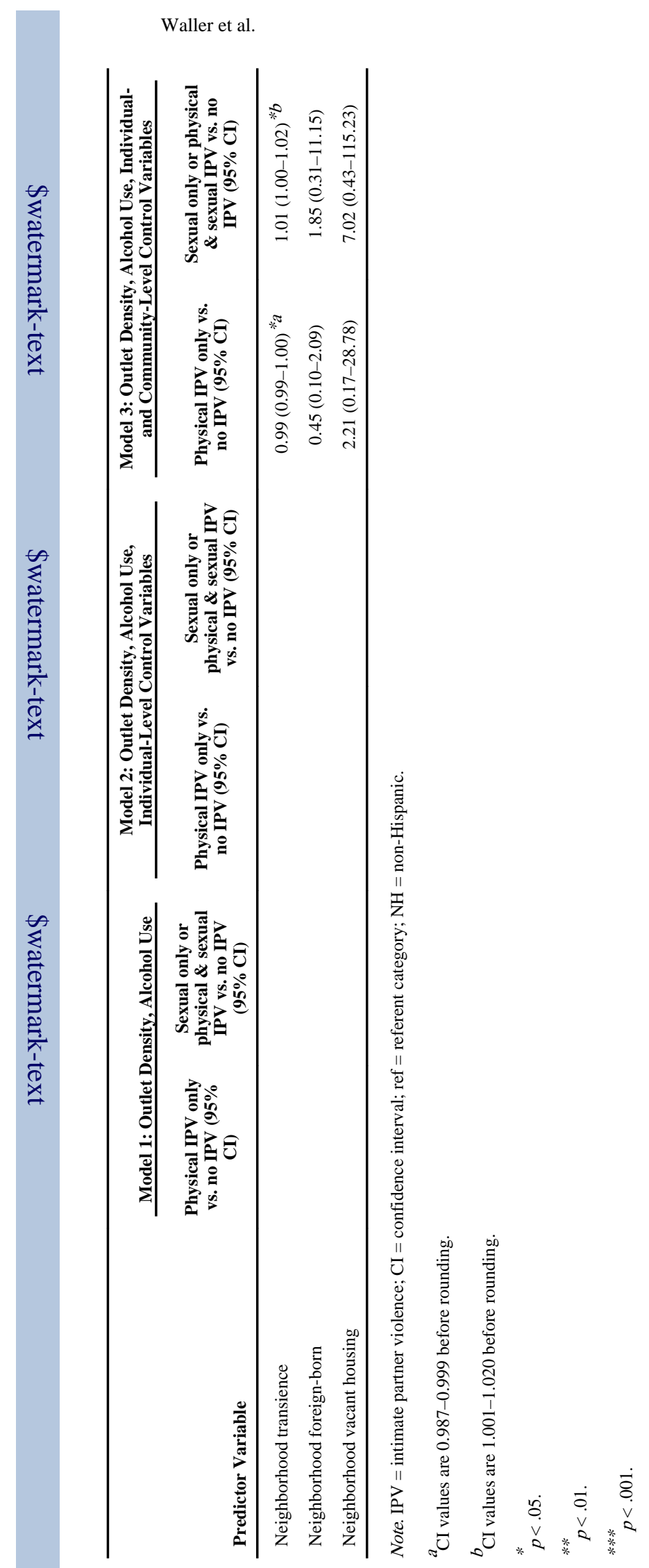

Violence Vict. Author manuscript; available in PMC 2013 January 01. 